\title{
COSTA RICA: FUERTE INTERDEPENDENCIA ENTRE ACTORES GENERA UN CONTEXTO DE PARÁLISIS Y ENFRENTAMIENTO POLÍTICO
}

\author{
Costa Rica: Strong Interdependence Among Political \\ Actors Results in a Context of Gridlock and Political Confrontation
}

\section{RONALD ALFARO-REDONDO}

Universidad de Costa Rica

\section{STEFFAN GÓMEZ-CAMPOS}

Universidad de Costa Rica

\begin{abstract}
RESUMEN
El 2015 estuvo marcado por una fuerte fragmentación partidaria en el Congreso, y la dificultad de crear grandes mayorías legislativas para tomar decisiones centrales en el sistema político. El Ejecutivo sufrió un fuerte desgaste de su imagen que dificultó la gestión de los asuntos públicos. Bajo tal escenario de alta interdependencia política, el resultado evidente es la anulación de los actores políticos y sus iniciativas, pues, al depender unos de otros, se encuentran sumidos en el plano de la inacción real.
\end{abstract}

Palabras clave: Acciones colectivas, Costa Rica, elecciones, fragmentación política, gestión política, relaciones Ejecutivo y Legislativo.

\begin{abstract}
2015 was marked by a strong party fragmentation in Congress, and the difficulty of creating large legislative majorities to make key decisions in the political system. The executive suffered a severe erosion of its credibility that hampered its capability on governance issues. Under such scenario of high political interdependence, the result is the cancellation of political actors and initiatives, which in practice are mired in stagnation.
\end{abstract}

Key words: Costa Rica, executive-legislative relations, elections, political parties, political gridlock, fragmentation. 


\section{TEMAS SALIENTES DE LA REALIDAD NACIONAL Y SU IMPACTO POLÍTICO}

\section{Coyuntura política}

Durante el 2015, tanto el Ejecutivo como el Legislativo se enfrentaron a constantes conflictos y eventos de alto perfil público. Estos eventos evidencian las dificultades del sistema político para resolver temas complejos bajo el actual escenario de alta fragmentación partidaria en el Congreso, con un poder ejecutivo que ha perdido credibilidad aceleradamente.

Las encuestas de opinión pública del Centro de Investigación y Estudios Políticos de la Universidad de Costa Rica (CIEP-UCR), muestran un fuerte desgaste en la percepción ciudadana sobre la gestión del gobierno y la figura del presidente Solís Rivera. Acá vale recordar que el Presidente ganó la elección de 2014 en segunda vuelta con el Partido Acción Ciudadana (PAC), partido que por primera vez accedió al control del Ejecutivo desde que se fundó en el 2000. El Presidente asumió funciones en mayo de 2014 con una amplia legitimidad proveniente de los más de 1,3 millones de votos obtenidos (el 77,8\% de los votos válidos) frente a 382.600 votos que obtuvo el Partido Liberación Nacional $(\mathrm{PLN})^{1}$ en la segunda vuelta.

En julio de 2014, a cien días de mandato, la evaluación era positiva con un 39\% que consideraba la gestión del gobierno Solís Rivera como buena y muy buena, y un 20\% como mala o muy mala. Cumplido el año de gobierno, en abril de 2015, ese balance se invirtió: casi la mitad de los entrevistados consideró que la gestión era mala o muy mala (49\%) y solo un $20 \%$ la evaluó positivamente.

La figura del Presidente se ha erosionado considerablemente en el mismo tiempo. En julio de 2014, los encuestados dieron una calificación promedio de 7,3 en una escala de 0 a 10. La última encuesta de 2015, en noviembre, muestra que esa calificación bajó hasta un 5,3 en la misma escala.

Estos datos son reflejo de la difícil situación que enfrenta el Ejecutivo para liderar los asuntos públicos. Este es un escenario de alta fragmentación partidaria, con una bancada legislativa disminuida del Partido Acción Ciudadana (PAC) -partido de gobierno- y una baja credibilidad del Ejecutivo, que vuelve muy complejo la toma de decisiones expeditas sobre aspectos centrales para el país.

La conformación del Directorio Legislativo es un ejemplo del difícil escenario que experimenta el PAC en el Congreso. Este partido llegó a la Presidencia de la República en mayo de 2014 con un fuerte mandato en las elecciones presidenciales, pero no así en las legislativas: obtuvo solo 13 de los 57 escaños del Congreso. Aun así, en el primer año de gestión la fracción oficialista logró presidir el Directorio Legislativo 2014-2015, en

1 En las elecciones del 2 de febrero de 2014 ningún partido obtuvo el $40 \%$ de los votos válidos para elegirse, de acuerdo con la normativa constitucional. Ello obligó a celebrar una segunda vuelta electoral entre los dos partidos más votados, el PAC y el PLN, en abril de 2014. Sin embargo, un mes antes de la elección, de forma inesperada el candidato del PLN decidió abandonar la contienda, y con ello, su aspiración presidencial. Este hecho generó un remezón político a lo interno del PLN con fuertes críticas a su candidato y el comando de campaña. 
alianza con otras dos agrupaciones parlamentarias: los partidos Unidad Social Cristiana (PUSC) y Frente Amplio (FA).

El Directorio posee atribuciones administrativas y políticas que influencian las dinámicas del Congreso costarricense. Por un lado, son los encargados de velar por el orden económico de este órgano, a través de nombramientos de personal clave para el funcionamiento interno de la asamblea y asignando los recursos financieros a las diferentes fracciones. Por otro lado, tienen la potestad de distribuir los proyectos de ley en las distintas comisiones permanentes y de nombrar a los diputados integrantes de dichos espacios, quienes se encargarán de la discusión y avance de estos expedientes en la corriente legislativa. Entre otras funciones, también son los encargados de presidir las sesiones plenarias.

Por ello, mantener el control del Directorio Legislativo es clave para el partido de gobierno. Sin embargo, el PAC tuvo que enfrentar diversos eventos de alto perfil público que debilitaron la alianza que los apoyó para la dirección del Congreso. Entre dichos eventos destacan la investigación, llevada a cabo por la Fiscalía General de la República, en contra de los integrantes del Directorio Legislativo debido a nombramientos en la parte administrativa y del cuerpo de asesores legislativos en el Congreso, que aparentemente incumplieron los procesos administrativos de la institución. En tales nombramientos fueron designados integrantes de las cúpulas partidarias del PAC y del PUSC.

Aunado a lo anterior, a inicios del 2015, se dio un proceso de resquebrajamiento de la alianza. Primero, la fracción del Frente Amplio (FA) decidió no renovar el apoyo al PAC para la segunda legislatura, debido a un distanciamiento con el Ejecutivo. Entre las razones que indicó este partido para retirar su apoyo se encuentra el descontento por el manejo de los problemas estructurales del país -como la concesión de ciertos permisos ambientales-, la búsqueda de más impuestos y el poco dinamismo del mercado laboral, temas todos sensibles para el FA de ideología de izquierda.

El PUSC, por su parte, inició negociaciones tempranas con el Partido Liberación Nacional (PLN) -que tiene la fracción con el mayor número de diputados, 18 en totalpara instaurar un Directorio integrado solo por opositores al gobierno. Finalmente, el interés de dos diputados del PAC de aspirar a la presidencia del Congreso generó una división interna del partido que no le hizo nada bien a sus intenciones de continuar al mando del Directorio Legislativo.

Con la elección del nuevo Directorio Legislativo, en mayo de 2015, un grupo de seis partidos de la oposición conformados por el PUSC, el PLN, el Movimiento Libertario (ML) y tres partidos del bloque evangélico (Renovación Costarricense, Restauración Nacional y Alianza Demócrata Cristiana) reunieron las fuerzas y los votos necesarios para conformar el Directorio Legislativo 2015-2016, presidido por un diputado del PUSC.

\section{Coyuntura socioeconómica}

Con respecto a los principales indicadores socioeconómicos, la revisión más general muestra que en Costa Rica persiste una desconexión entre la ampliación de capacidades de la ciudadanía y el objetivo de una mayor equidad. Es decir, el país ha logrado ampliar los 
niveles de desarrollo humano para la población en general, sin embargo, la desigualdad sigue en aumento y se constituye en uno de los principales desafíos sociales.

Los datos así lo demuestran. Por ejemplo, la esperanza de vida se estima en 79,9 años, una de las más altas de América Latina y similar a la de países desarrollados del resto del mundo. Otro indicador de desarrollo humano utilizado para comparaciones internacionales es la tasa de mortalidad infantil, que para el primer semestre del 2015 se ubicó en 8,4 por mil nacimientos. Ese sigue siendo un buen resultado en el contexto internacional.

No obstante, la incidencia de la pobreza estimada con el método de línea de pobreza se ha mantenido cercano al $20 \%$ de los hogares desde mediados de la década de los noventa. Según la Encuesta Nacional de Hogares (Enaho) 2015, del Instituto Nacional de Estadística y Censo (INEC), se estima que 317.660 hogares son pobres, es decir un 21,7\%. En relación con el 2014 representa una disminución de 0,6 puntos porcentuales, cambio que no es estadísticamente significativo. La pobreza extrema se sitúa en 7,2\%, equivalente a 104.712 hogares.

En términos absolutos, estos datos indican que un total de 1.137.881 personas son pobres (23,6\% de la población), de las cuales 374.385 son pobres extremos $(7,8 \%)$.

En materia de desigualdad el país no muestra avances durante el 2015. El coeficiente de Gini se mantuvo en 0,516, sin cambios con respecto al 2014 y similar a la de los últimos cinco años. Esto significa que el país se mantiene estancado en sus máximos niveles históricos en materia de desigualdad del ingreso.

El escenario socioeconómico se ha vuelto más complejo dado el aumento en el desempleo. La Encuesta Continua de Empleo (ECE) realizada por el INEC muestra que la tasa de desempleo del último trimestre del 2013 mostró el nivel más bajo (8,3\%), sin embargo, durante el 2014 y los dos primeros trimestres del 2015 esta tasa se ha mantenido cercana al 10\%. Bajó levemente a un 9,2\% en el tercer trimestre de 2015. Los grupos más afectados siguen siendo las personas pobres (sobre todo extremos pobres), las mujeres, los jóvenes y las personas con baja calificación.

El escenario macroeconómico no permite dar un impulso fuerte al desarrollo humano del país. La producción del país creció un 2,8\% en 2015, con mayor dinamismo en el segundo semestre del año. El impulso provino de la demanda interna y del sector de servicios. Aunque positivo, el crecimiento sigue estando por debajo del 5\% promedio que se experimentó en los años previos a la crisis económica de 2008-2009.

El otro gran problema económico, con fuertes repercusiones políticas, es el de las finanzas públicas. Se estima que el déficit para el gobierno central es equivalente a un 5,9\% del PIB. Las cifras a noviembre del 2015 muestran que los ingresos tributarios aumentaron $9 \%$, en tanto que los gastos corrientes (excluidos los intereses) lo hicieron a una tasa de $7,3 \%$. Aunque se han hecho esfuerzos por revertir la tendencia del déficit, el país ha sido incapaz desde el año 2010 de acordar una reforma tributaria que resuelva los problemas actuales del déficit.

En 2011, bajo el mandato de la presidenta Chinchilla se impulsó un Plan Fiscal que finalmente no se puso en práctica por la declaración de inconstitucionalidad realizada 
por la Sala Constitucional, ante errores en el trámite de aprobación de dicho proyecto. El nuevo gobierno del presidente Solís Rivera que inició en mayo del 2014, entró con la consigna de no aprobar impuestos durante los dos primeros años de gobierno. No obstante, la fuerte carga del déficit ha hecho que el gobierno plantee la discusión fiscal antes de llegar a la mitad de su período de mandato, aunque sin resultados positivos hasta el momento.

\section{PROCESO ELECTORAL PARA COMICIOS MUNICIPALES}

Durante la segunda mitad del 2015 se realizó la campaña electoral para los comicios municipales que se celebraron el 7 de febrero de 2016. En esta oportunidad se designaron un total de 6.069 representantes políticos y compitieron más de 30.000 candidatos en los 81 municipios y 480 distritos del país. Dicho proceso tiene especial relevancia por ser la primera vez que se elige en un solo proceso a todas las autoridades municipales, luego de la unificación de las elecciones de regidores, alcaldes, síndicos, concejales de distrito, intendentes y concejales municipales de distrito.

La reforma al Código Municipal de 2007 (Ley N N 8611) ordenó la separación de las elecciones municipales y las nacionales, en tanto que la modificación del artículo 150 del Código Electoral de 2009 estableció un nuevo calendario electoral, en el cual se estipula que los comicios municipales se realizarán el primer domingo de febrero dos años después de las elecciones presidenciales y legislativas.

Vale anotar que las municipalidades en Costa Rica son entidades estatales que poseen autonomía política, administrativa y financiera. Los gobiernos locales pertenecen a la esfera de lo que comúnmente se conoce como sector público descentralizado que reúne a los ministerios, poderes de la República e instituciones autónomas. El mandato de los representantes locales no está sujeto a autoridades de nivel central o regional. En lo que respecta a la autonomía administrativa, los gobiernos locales tienen la posibilidad de definir sus propias disposiciones para regular su organización, presupuesto y funcionamiento interno. No obstante, las municipalidades no tienen potestad para crear o modificar impuestos. Esa atribución reside en la Asamblea Legislativa. Para el desempeño de sus funciones, las municipalidades cuentan con recursos financieros y humanos propios. La jurisdicción territorial de los gobiernos locales es el municipio. El municipio (también conocido como cantón) es el territorio geográfico en el que los ayuntamientos ejercen su rol de administradores de los bienes y servicios comunales y gobierno local.

\section{Principales resultados electorales}

De los 3.178.364 electores habilitados para sufragar solo un 35\% hizo uso de este derecho (siete puntos porcentuales más que en la última contienda en 2010). El ausentismo de votantes en las urnas fue alto en comparación con procesos similares en otros países y con el resto de elecciones nacionales, pero se mantuvo estable respecto de lo acontecido entre 2002 y 2010 (76\%, 77\% y 72\% respectivamente). 
En estos comicios, una vez más los electores de localidades urbanas se abstuvieron de participar en mayor medida que los de comunidades rurales. Los cantones cabecera de provincia (San José, Alajuela, Heredia, Cartago, Puntarenas, Liberia y Limón) encabezan los lugares con mayor ausentismo en las urnas en las respectivas provincias. En este grupo también se incluyen centros densamente poblados, como Desamparados, Goicoechea, La Unión y Tibás. En estos cantones el abstencionismo superó el 70\% de los electores. Por otra parte, los cantones con menor abstencionismo son principalmente rurales, y entre ellos sobresalen Montes de Oro, San Mateo, Tarrazú, Turrubares y Hojancha (localidades en las que alrededor del $65 \%$ de los electores concurrieron a las urnas). Además, una parte importante de estos cantones pertenecen a las provincias de Guanacaste, Puntarenas y Limón que tienen mayores niveles de abstencionismo en las elecciones presidenciales y legislativas.

Este patrón de comportamiento, que difiere de lo que sucede en las elecciones nacionales, puede encontrar explicación en el hecho de que para las comunidades rurales los gobiernos locales revisten una mayor importancia y tienen una mayor presencia institucional que las entidades del gobierno central. El análisis de los patrones de abstencionismo revela importantes similitudes a lo largo del tiempo, es decir, las municipalidades que reportan los niveles más altos y más bajos de participación tienden a ser las mismas en las cuatro elecciones analizadas.

Los resultados electorales además confirman la consolidación del multipartidismo producto de un afianzamiento de los partidos locales, el debilitamiento del Partido Liberación Nacional (PLN) -el partido de más larga trayectoria- y la apatía del electorado a pesar de un pequeño repunte en la participación.

El análisis del desempeño de los partidos políticos muestra que la agrupación oficialista Acción Ciudadana (PAC) obtuvo en 2016 la misma cantidad de alcaldías que en 2010, y el PLN fue el partido que más alcaldías conquistó en todo el país. En marcado contraste con comicios anteriores, el partido que triunfó en las últimas elecciones presidenciales no tiene bajo su control la mayor cantidad de ayuntamientos. Si bien los datos preliminares apuntan a un debilitamiento del respaldo del liberacionismo producto de su derrota en 4 de los 7 municipios cabecera de provincia, el PLN mantiene su hegemonía en las elecciones municipales desde el 2006. El apoyo hacia el Partido Unidad Social Cristiana (PUSC) -el segundo de mayor tradición- creció significativamente comparado con el registrado en 2010 (Cuadro 1). El marcado carácter territorial de estas elecciones municipales les permite a las agrupaciones con maquinarias electorales y dirigencia local más experimentadas movilizar a sus electores de manera más efectiva.

Finalmente, esta elección muestra un aumento significativo en la oferta partidaria a nivel municipal. Para el 2016 la cantidad de agrupaciones políticas con posibilidades de competir electoralmente fue más del doble de la registrada en 2002, pues la cifra pasó de 34 a 86 . De estas últimas, 17 son partidos de escala nacional, 12 provinciales y 57 cantonales, fundados en 39 localidades distintas. Esto significa que casi la mitad de los cantones del país (un $48 \%$ ) tuvo al menos un partido de base local que pudo presentar candidaturas en los comicios municipales. 
Cuadro 1. Cantidad de alcaldías según partido político 2002-2016

\begin{tabular}{|c|c|c|c|c|c|}
\hline \multirow{2}{*}{ Partido político } & \multicolumn{4}{|c|}{ Año de la elección } & \multirow{2}{*}{$\begin{array}{l}\text { Diferencia } \\
2016-2010\end{array}$} \\
\hline & 2002 & 2006 & 2010 & $2016^{\mathrm{b} /}$ & \\
\hline Liberación Nacional (PLN) & 27 & 59 & 59 & 50 & -9 \\
\hline Unidad Social Cristiana (PUSC) & 48 & 11 & 9 & 14 & 5 \\
\hline Acción Ciudadana (PAC) & 1 & 4 & 6 & 6 & 0 \\
\hline Movimiento Libertario (ML) & 0 & 1 & 2 & 0 & -2 \\
\hline Otros partidos a/ & 5 & 6 & 5 & 11 & 6 \\
\hline Total & 81 & 81 & 81 & 81 & \\
\hline
\end{tabular}

a/ La categoría Otros partidos incluye 30 agrupaciones en 2002, 39 en el 2006, 42 en el 2010 y 55 en el 2016.

b/ Datos preliminares al 15 de febrero de 2016.

Fuente: Elaboración propia con base en datos del Tribunal Supremo de Elecciones (TSE).

En este tema es preciso indicar que, por mandato de la Sala Constitucional, desde 2010 los partidos no están obligados a realizar asambleas distritales como requisito para inscribir o renovar sus estructuras ante el Tribunal Supremo de Elecciones. Ello ha implicado un ahorro significativo en recursos y logística para las agrupaciones políticas. Así pues, se redujeron los obstáculos para la creación de nuevos partidos y los datos para las elecciones municipales lo confirmaron. Este es un hecho positivo para el sistema político, en la medida en que representa una mayor pluralidad y una ampliación de las formas de organización para la competencia electoral, ambos factores claves para el fortalecimiento de la democracia.

\section{DESEMPEÑO DEL PODER EJECUTIVO}

El presidente Solís Rivera llegó a la silla presidencial con el partido Acción Ciudadana, e inició funciones en mayo de 2014. Para analizar el desempeño durante la primera parte de su mandato, en esta sección se analizan dos áreas de interés. Una es la inestabilidad del gabinete en óptica comparada. La otra refiere a las relaciones entre el ejecutivo y el legislativo en las convocatorias de proyectos de ley que hace el primero ante el Congreso durante la primera legislatura.

En lo que respecta a la gestión política, durante su primer año el ejecutivo sufrió una alta rotación de los miembros de su gabinete -y de otras instancias, algunos de los cuales salieron en medio de shocks políticos que afectaron su imagen y legitimidad-. El gabinete presidencial es una entidad de la mayor relevancia, pues sus miembros son los encargados de ejecutar, en cada uno de los ministerios, el proyecto político del Poder Ejecutivo. La designación ministerial es, por tanto, una decisión estratégica. Es importante tener en cuenta que la inestabilidad no puede medirse a partir de la frecuencia de los cambios en el gabinete, ya que el Presidente puede hacer ajustes en su equipo de trabajo, o las 
personas nombradas pueden renunciar por motivos personales. El fenómeno que aquí interesa son las salidas documentadas que se produjeron en medio de crisis políticas de alto perfil mediático.

Para ello se hizo una revisión de los cambios ocurridos durante el primer año de gestión de los últimos cinco gobiernos, y se encontró que las administraciones Chinchilla Miranda (2010-2014) y la actual, Solís Rivera, experimentaron las mayores rotaciones en las altas jerarquías del poder ejecutivo. En ambos casos, cinco ministros y ministras dejaron sus carteras durante los primeros doce meses de funciones. El gobierno de Arias Sánchez (2006-2010), por el contrario, tuvo el equipo más estable. Los datos revelan además que el ministerio con mayores relevos en términos agregados es el de Turismo, seguido por el de Ciencia, Tecnología y Telecomunicaciones, Presidencia y Seguridad Pública.

En el primer año de las dos últimas administraciones resaltan los cambios en el Ministerio de la Presidencia, una cartera clave en la gestión política del Ejecutivo, tanto en su relación con el Congreso como con las organizaciones gremiales y muchos otros sectores. La salida temprana de sus titulares es un indicador de dificultades para gestionar satisfactoriamente conflictos de alto perfil público a los que se enfrentó el gobierno, lo que en ambos casos forzó su retiro del gabinete (Cuadro 2).

Cuadro 2. Rotación de ministros en el gabinete durante el primer año de gobierno, por administración y ministerio. 1998-2015

\begin{tabular}{|c|c|c|c|c|c|c|}
\hline \multirow[b]{2}{*}{ Ministerio } & \multicolumn{5}{|c|}{ Administración } & \multirow{2}{*}{$\begin{array}{c}\text { Total } \\
\text { general }\end{array}$} \\
\hline & $\begin{array}{l}\text { Rodríguez } \\
\text { Echeverría }\end{array}$ & $\begin{array}{l}\text { Pacheco de } \\
\text { la Espriella }\end{array}$ & $\begin{array}{c}\text { Arias } \\
\text { Sánchez }\end{array}$ & $\begin{array}{l}\text { Chinchilla } \\
\text { Miranda }\end{array}$ & $\begin{array}{l}\text { Solís } \\
\text { Rivera }\end{array}$ & \\
\hline Turismo & 1 & 1 & & 1 & 1 & 4 \\
\hline $\begin{array}{l}\text { Ciencia, Tecnología y } \\
\text { Telecomunicaciones }\end{array}$ & & & & 1 & 1 & 2 \\
\hline Presidencia & & & & 1 & 1 & 2 \\
\hline Seguridad Pública & & & & 1 & 1 & 2 \\
\hline Condición de la Mujer & 1 & & & & & 1 \\
\hline Coordinación del Sector Social & & 1 & & & & 1 \\
\hline Deporte & & & & 1 & & 1 \\
\hline Educación & 1 & & & & & 1 \\
\hline Justicia y Gracia & & 1 & & & & 1 \\
\hline $\begin{array}{l}\text { Planificación Nacional } \\
\text { y Política Económica }\end{array}$ & & 1 & & & & 1 \\
\hline $\begin{array}{l}\text { Producción } \\
\text { (MAG + MEIC) }\end{array}$ & & & 1 & & & 1 \\
\hline Salud & & & & & & 1 \\
\hline Cambios totales & 3 & 4 & 1 & 5 & 5 & 18 \\
\hline
\end{tabular}

Fuente: Vigesimoprimer Informe Estado de la Nación, 2015. 
El Poder Ejecutivo siempre está expuesto a shocks internos y externos que lo obligan a reaccionar. Un Presidente puede despedir a algunos de sus ministros para que recaiga en ellos la responsabilidad por escándalos o fracasos de la gestión gubernamental, o bien cuando ejercen mal su rol como intermediarios ante otras fuerzas sociales o políticas (Martínez-Gallardo, 2011; Indridason y Kam, 2008). La situación se torna problemática cuando una alta proporción de las salidas se asocia a crisis políticas, pues en esos casos el recambio añade inestabilidad a los cuerpos encargados de conducir los asuntos de Estado.

Lo anterior sucedió en el primer año de las administraciones Chinchilla Miranda y Solís Rivera. En este último caso, la mayoría de las renuncias ministeriales ocurridas entre el $1^{\circ}$ de mayo de 2014 y el 30 de abril de 2015 se debió a crisis políticas relacionadas con problemas de gestión política o institucional. Así, la jerarca del Ministerio de Ciencia, Tecnología y Telecomunicaciones (Micitt), presentó su renuncia a causa de una serie de cuestionamientos sobre el borrador de un proyecto de ley de radio y televisión que, aparentemente, atentaba contra la libertad de expresión; poco después, el ministro de la Presidencia fue destituido por el desgaste de su imagen política y como resultado de diversos conflictos y denuncias por presuntos ofrecimientos irregulares de puestos en embajadas, a funcionarios que lo informaron a los medios de comunicación, y la ministra de Cultura se retiró del cargo luego de las críticas que recibiera por el fracaso en la organización del Festival Internacional de las Artes (FIA) 2015. A estos cambios se sumaron las renuncias de los ministros de Salud y Seguridad, por razones personales y profesionales. Además de la inestabilidad en el gabinete, durante este año también hubo otras salidas que afectaron la gestión del Ejecutivo, entre ellas las de cinco viceministros, seis asesores del gobierno y miembros de la Juventud del PAC y tres embajadores, estos últimos por expresar opiniones personales que resultaban inapropiadas estando en el ejercicio de sus funciones.

En suma, el gabinete de la actual administración ha sufrido una alta inestabilidad, solo similar a la ocurrida durante el primer año de gestión de la presidenta Chinchilla Miranda. Las salidas de ministros, ministras y otros funcionarios durante el período 2014-2015 estuvieron relacionadas con escándalos de alto perfil ante la opinión pública. A ello hay que agregar diversos conflictos institucionales o con otros actores por coyunturas específicas, como las huelgas de los educadores y de los trabajadores del puerto de Moín en la provincia de Limón, o las críticas por el fuerte incremento (19,7\%) del Presupuesto de la República. El balance para el ejecutivo es negativo porque, en algunos casos, los problemas de conducción política lo mantuvieron replegado durante este primer año, y además porque generaron un desgaste en la imagen pública del gobierno y del Presidente mismo, de acuerdo con las encuestas de opinión pública realizadas por el CIEP-UCR tal y como se referenció anteriormente.

La segunda área de análisis tiene que ver con la agenda legislativa que propone el ejecutivo y la consecución de la misma. Al respecto, las estrategias del Ejecutivo para promover sus iniciativas en el Congreso han variado desde que en el país predominaba un sistema bipartidista, en los años noventa. Su principal herramienta es la convocatoria y retiro de proyectos para discusión parlamentaria, lo que ocurre durante seis meses 
al año en lo que se conoce como las sesiones extraordinarias. Estas se reparten en dos períodos, el primero en agosto y el segundo entre diciembre y abril. ${ }^{2}$ En ese lapso el Ejecutivo decide qué se discute en la Asamblea Legislativa.

No hay reglas formales para la convocatoria de proyectos de ley, pero sí es posible observar el comportamiento y, a partir de él, deducir la estrategia utilizada por cada gobierno. Para ello el Programa Estado de la Nación construyó una base de datos que incluye todas las convocatorias y desconvocatorias de proyectos de ley en sesiones extraordinarias, durante el primer año de gestión de las siete administraciones que gobernaron el país entre 1990 y $2015 .^{3}$

Los datos muestran que en el ámbito legislativo el Ejecutivo enfrentó un severo bloqueo: en los períodos de sesiones extraordinarias, el actual gobierno del presidente Solís Rivera obtuvo la tasa de éxito de aprobación de leyes más baja desde 1990, de modo que fue poco lo que pudo avanzar con sus iniciativas de ley.

$\mathrm{Al}$ analizar en detalle es posible determinar que, conforme pasa el tiempo, el Ejecutivo tiende a convocar cada vez más proyectos de ley en su primer año de gestión. La menor cantidad registrada corresponde a la administración Calderón Fournier, con 105, y la mayor a la del presidente Solís Rivera, con 315. Ciertamente la herramienta de convocatoria y desconvocatoria puede ser de utilidad para los objetivos del gobierno de turno, pues, usada estratégicamente, brinda la flexibilidad de incluir y excluir un proyecto de la corriente legislativa de acuerdo con el ambiente político o la urgencia de la reforma. Esto se hace para desbloquear la agenda de ciertas comisiones y lograr que avancen las iniciativas clave para el Ejecutivo.

Cuando un Ejecutivo convoca -y mantiene- pocos proyectos de ley durante las sesiones extraordinarias, suele ser por la necesidad de concentrar toda la discusión en una agenda reducida y prioritaria. Cuando una iniciativa es convocada en varias ocasiones puede deberse a constantes cambios del ambiente político en torno a ella, o bien al interés de modificar su posición en el orden del día.

Sin embargo, indistintamente del procedimiento utilizado, la evidencia muestra que la estrategia de múltiples convocatorias no ha dado resultados positivos en el avance de la agenda del Ejecutivo. Esto fue muy claro durante el primer año de la administración Solís Rivera, en el cual se registró la mayor cantidad de proyectos convocados y, a la vez, la menor tasa de éxito en el período estudiado. De las 315 iniciativas sometidas a discusión en sesiones extraordinarias entre 2014 y 2015, solo se aprobaron ocho, ${ }^{4}$ para

\footnotetext{
El año legislativo en Costa Rica va del 1 de mayo de un año al 30 de abril del año siguiente.

La construcción de la base de datos de decretos ejecutivos del Programa Estado de la Nación (PEN) estuvo liderada por los investigadores Felipe Alpízar y Alina Menocal de la Universidad de Costa Rica, y contó con la colaboración y ajustes metodológicos de Steffan Gómez Campos y María Estelí Jarquín del equipo técnico del PEN.

4 Los ocho expedientes legislativos propuestos por el Ejecutivo y aprobados fueron: Expediente 18339 Modificación del artículo 4 de la Ley de la Defensoría de los Habitantes de la República Nº 7319 del 17 de noviembre del año 1992 y sus reformas; Expediente 19174 Reforma del Transitorio V de la Ley N ${ }^{\circ} 8783$ Reforma de la Ley de Desarrollo Social y de Asignaciones Familiares N 5662; Expediente 19360 Modificación a la Ley $\mathrm{N}^{\circ}$ ley de presupuesto extraordinario de la república para el ejercicio económico 2014 y segundo presupuesto
} 
Gráfico 1. Tasa de éxitoa/ del poder Ejecutivo en sesiones extraordinariasb/, según administración

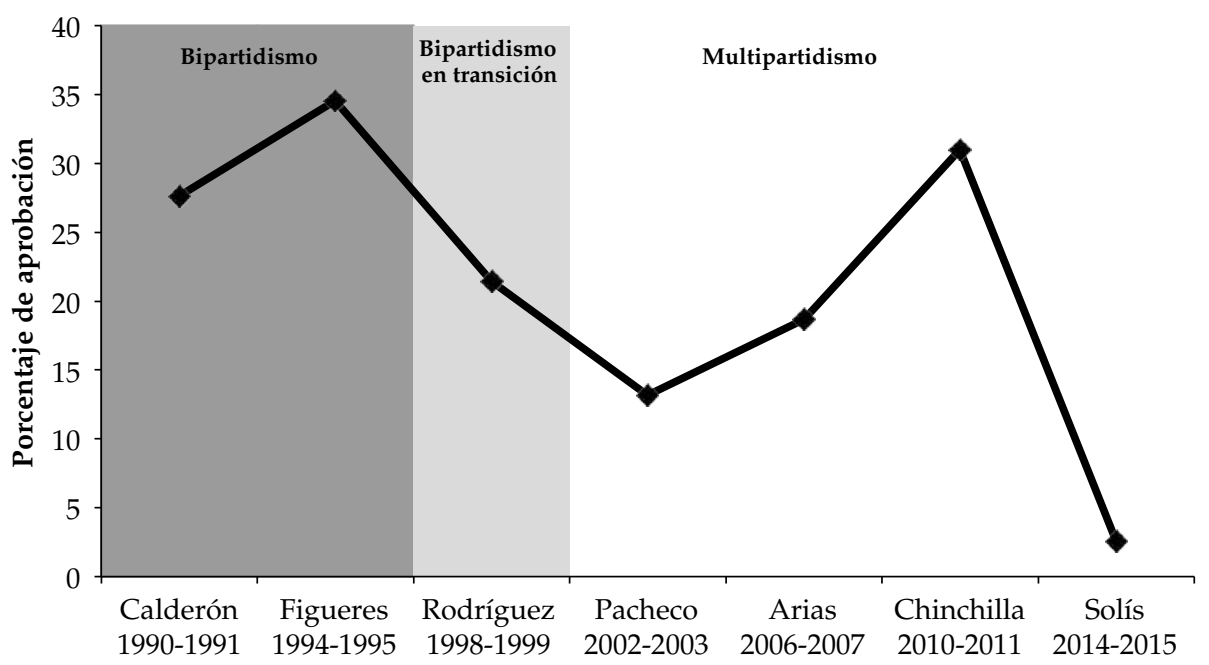

a/ Es la relación entre el número de leyes aprobadas y el total de leyes convocadas por el Ejecutivo en las sesiones extraordinarias en primeras legislaturas.

b/ Se consideran únicamente las primeras legislaturas de cada administración.

Fuente: Elaboración propia con base en el Vigesimoprimer Informe Estado de la Nación, 2015.

una tasa de éxito de 2,5\%. El segundo peor resultado, pero muy distante, se dio durante la administración Pacheco de la Espriella. Por el otro lado, el gobierno con la mejor tasa de éxito fue el de Figueres Olsen, con 34,6\%, seguido por los de Chinchilla Miranda y Calderón Fournier (Gráfico 1).

Con una perspectiva de más largo plazo estos datos dan cuenta de la debilidad relativa del Ejecutivo, ya que en promedio, desde 1990, solo ha logrado la promulgación de dos de cada diez leyes que convocó en sesiones extraordinarias durante su primer año de gestión. La relevancia de este hecho se incrementa al considerar, como lo indica la literatura especializada, que el primer año legislativo es el momento más favorable para avanzar con la agenda de interés para el gobierno.

En suma, Costa Rica experimenta un escenario adverso para que el Presidente de turno pueda tener amplios poderes sobre la agenda legislativa, tal como lo muestran los datos

extraordinario de la república para el ejercicio económico 2014; Expediente 19236 Cambio de nomenclatura del cantón número sexto de la provincia de Puntarenas para que en adelante se denomine Quepos; Expediente 18887 Ley de Desarrollo de Obra Pública corredor vial San José-San Ramón mediante fideicomiso; Expediente 18945 Aprobación del Financiamiento al proyecto, Rehabilitación y extensión de la ruta Nacional N³2sección ruta 4 -Limón; Expediente 19464 Modificación a la Ley No 9289 Ley de Presupuesto Ordinario y Extraordinario de la República para el ejercicio económico del 2015 y el Primer Presupuesto Extraordinario de la República para el ejercicio económico del 2015; Expediente 18877 adición de un inciso d) al artículo 2) de la Ley N 8957 del 17 de junio del 2011 Creación de un bono para la segunda vivienda familiar en primera y en segunda edificación. 
empíricos antes presentados. Ello es así debido a una multiplicidad de factores, entre los que destacan los reducidos poderes del ejecutivo, tal y como lo ha documentado García (2009); que los partidos en el poder no han contado con mayorías en el Congreso; así como el progresivo aumento en el número efectivo de partidos políticos, que ha desembocado en el sistema altamente fragmentado que existe en la actualidad.

\section{DESEMPEÑO DEL PODER LEGISLATIVO}

El análisis de esta sección se basa en tres criterios metodológicos trazados por el Programa Estado de la Nación (PEN). El primero consiste en la revisión del número y tipo de leyes aprobadas. Si bien la cantidad no es el único -ni el más importante- indicador para esta evaluación, el seguimiento por tipos de leyes sí permite una aproximación a las prioridades que tuvo el Congreso durante el año en estudio y la comparación con años anteriores. El segundo criterio es el estudio de lo que el PEN denomina la oferta y la demanda legislativas. Se trata de la comparación entre las leyes aprobadas (oferta) y una agenda de proyectos que diversos sectores de la opinión pública consideran prioritarios para el país (demanda). El tercer criterio se usa como un indicador indirecto (o proxy) de la calidad de la legislación: se analiza cada una de las leyes aprobadas para determinar si genera obligaciones para el Estado o amplía derechos ciudadanos, y si provee los recursos necesarios para su cumplimiento. Cuando esto último no ocurre, se produce el fenómeno legislativo denominado "promesa democrática sin sustento económico".

Los datos recopilados muestran que, durante el período 2014-2015, el desempeño legislativo fue insuficiente en términos de una representación política eficaz. La nueva conformación del Congreso plantea un escenario adverso para el partido de gobierno, el PAC, pues por primera vez el partido oficialista no tiene la bancada más numerosa, como en los años anteriores. Además, esta asamblea alcanzó el mayor nivel de fragmentación partidaria en la historia del país, no solo medida por el número efectivo de partidos parlamentarios (NEPp) -que es de 4,9 y consolida el formato multipartidista- sino también porque esta vez nueve agrupaciones políticas lograron representación parlamentaria, el número más alto desde 1953.

Así pues, el balance en el Congreso es insuficiente de acuerdo con una serie de indicadores del desempeño: la legislatura 2014-2015 tuvo una baja producción de leyes, y con ello, un escaso aporte al desarrollo humano. Además, muy poco de lo que se aprobó fue considerado como prioritario, de acuerdo con una consulta a los principales sectores de opinión y expertos consultados por el Programa Estado de la Nación para el análisis del Congreso. Como aspecto positivo cabe señalar el descenso en la promulgación de leyes sin el debido sustento económico.

Con respecto a la cantidad de leyes aprobadas y su desglose por tipos, la información disponible refleja que, entre las primeras legislaturas, la de 2014-2015 ha sido la menos productiva desde 1990. Se aprobó un total de 47 leyes, muy por debajo de las 73 promulgadas en el primer año de la administración Rodríguez Echeverría (1998-1999), que representan el segundo valor más bajo de la serie histórica. De esas 47 leyes, solo 
Gráfico 2. Total de leyes y de legislación sustantivaa/ aprobadas (primeras legislaturas de cada administración)

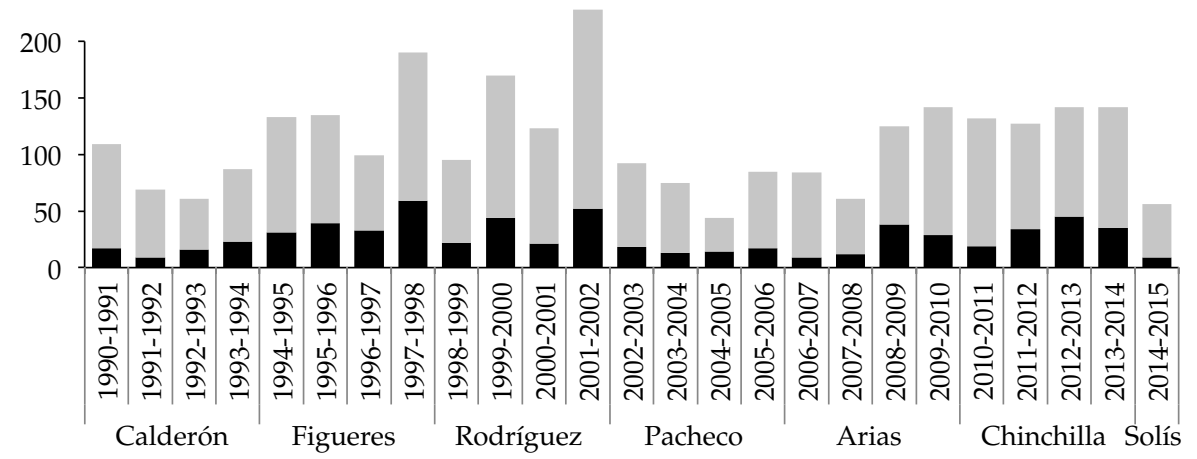

— Legislación sustantiva $\square$ Total de leyes

a/ La legislación sustantiva tiene efectos directos sobre el desarrollo humano. No se incluyen tratados internacionales.

Fuente: Vigesimoprimer Informe Estado de la Nación, 2015.

nueve son de tipo sustantivo, es decir, favorecen el desarrollo humano porque amplían o generan nuevos derechos a la población, o asignan competencias al Estado (Gráfico 2).

Un segundo indicador del desempeño legislativo es la relevancia de las leyes promulgadas. Realizar una evaluación en ese sentido no es fácil; requeriría un estudio caso por caso sobre los alcances y sectores involucrados, así como un análisis costo-beneficio de lo que implica asignar recursos a una población o área, en lugar de otra. Se trata de un trabajo exhaustivo, que ni el mismo Congreso realiza de previo a la aprobación de los proyectos de ley, precisamente por la gran cantidad de iniciativas que transitan por la corriente legislativa.

Una alternativa para examinar la relevancia de las leyes ha sido, entonces, replicar la metodología propuesta por Feoli para el Programa Estado de la Nación (2008, 2009, 2010 y 2011) sobre la oferta y la demanda legislativas. En pocas palabras, es un análisis que compara el contenido de la legislación aprobada durante el año en estudio, con los asuntos que sectores expertos y de la opinión pública han señalado como prioritarios para el país. ${ }^{5}$ Se parte de una premisa: que los principales medios de comunicación escrita, junto con un amplio grupo de representantes de la academia, el sector empresarial y diversos

5 El indicador de demanda legislativa está conformado por dos componentes. En primera instancia, se recopilan y se establece la frecuencia de aparición de los temas legislativos más abordados en las páginas editoriales de tres de los principales medios de prensa del país: La Nación, El Diario Extra y La República. Esto se complementa con una consulta por vía electrónica sobre los principales temas legislativos. En este caso dicha consulta fue respondida por 52 personas expertas de reconocida trayectoria en diversos campos: político, académico, empresarial, sociedad civil organizada y medios de comunicación masiva. Este grupo no constituye una muestra probabilística de los sectores correspondientes, es seleccionada bajo criterio experto. Por tal motivo los datos constituyen una aproximación con limitaciones (o proxy) para la inferencia y comparación, pero no por ello menos válida para la revisión sistemática de la relevancia de las leyes aprobadas. 
gremios, tienen el conocimiento necesario para identificar una agenda de proyectos de ley de alta relevancia nacional. Bajo tal lógica es posible contrastar esa agenda (demanda) con lo que el Congreso finalmente aprobó (oferta) y ver en qué medida coinciden. Si hay altos grados de convergencia, la legislación promulgada se considera relevante, y por el contrario, si la divergencia es alta, indicaría períodos de legislación menos relevantes.

La información recopilada permitió determinar que en la primera legislatura de la administración Solís Rivera hubo una muy alta divergencia entre la oferta y la demanda legislativas. De las 86 iniciativas identificadas como prioritarias por los principales sectores de la opinión pública y personas expertas, solo ocho fueron aprobadas por el Congreso. Entre estas destaca la Ley de Presupuesto de la República para el año 2015, que fue objeto de fuertes discusiones entre los actores políticos porque implicó un aumento sustantivo del gasto público, en un escenario de severo déficit fiscal. También se aprobó la reforma al Sistema de Banca para el Desarrollo y el fideicomiso para la construcción del corredor vial San José-San Ramón, que eran demandados por amplios sectores de la población.

El balance muestra que el $91 \%$ de la agenda demandada no fue atendido, valor que corresponde a la mayor brecha entre oferta y demanda legislativas desde que se mide este indicador (Gráfico 3). Entre los proyectos altamente demandados, pero no aprobados destacan la reforma al impuesto sobre la renta, la ley de sociedades de convivencia para personas del mismo sexo, las reformas al Reglamento Legislativo y la ley de empleo público.

El análisis del desempeño legislativo también considera la calidad de la legislación. Para ello se revisa cada una de las leyes que se promulgan y se identifica su alcance, según sea que amplía derechos anteriormente reconocidos a la población, o bien que asigna nuevas competencias y compromisos al Estado. Cuando una ley cumple con alguno de estos criterios se dice que es una promesa democrática, por cuanto genera expectativas en la

Gráfico 3. Porcentaje de la demanda legislativaa/ no atendida por el Congreso

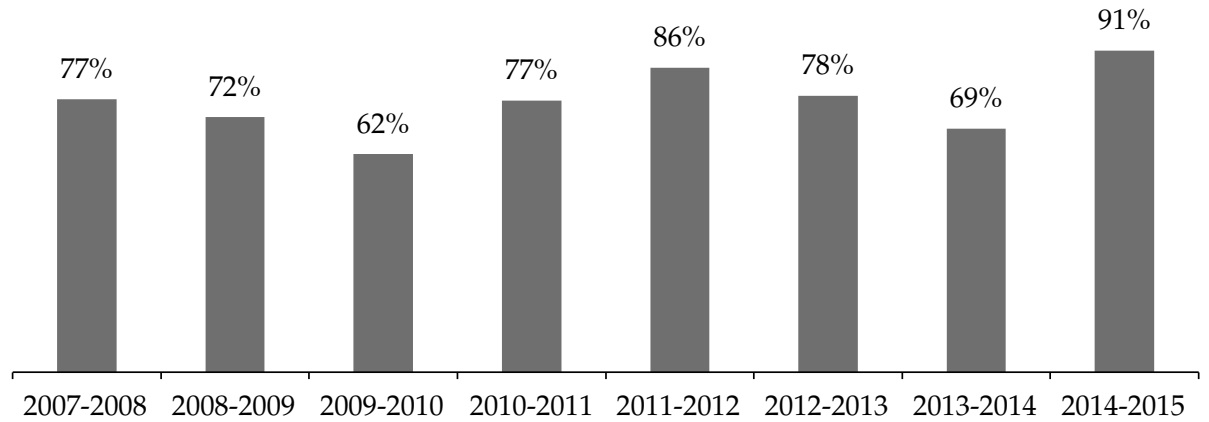

a/ La demanda legislativa refiere al conjunto de iniciativas que, a juicio de importantes sectores de la opinión pública y expertos, son prioritarias para el país.

Fuente: Elaboración propia con base en el Vigesimoprimer Informe Estado de la Nación, 2015. 
ciudadanía. Pero además la calidad implica que esa legislación debe proveer las fuentes de financiamiento y otros recursos necesarios para concretar la promesa realizada. En caso contrario se estaría en una situación de "promesa democrática sin sustento económico" $\mathrm{y}$, por ende, con altas probabilidades de incumplimiento del mandato legal. Cuando esto ocurre es de esperar que la población se muestre insatisfecha con el Congreso y, en general, con el sistema político, tal como ha ocurrido en el país en las últimas décadas.

Bajo esta perspectiva se observa que, desde inicios de los años noventa, el Congreso no ha producido leyes acordes con los estándares mínimos de calidad. Entre 1990 y 2015, en el 52,5\% de las 860 leyes con mandatos garantistas no se identificaron con claridad las fuentes de financiamiento para su concreción. El comportamiento anual muestra altibajos, pero nunca una reducción significativa de este fenómeno en los últimos veinticinco años.

No se cuenta con información suficiente para explicar las razones por las cuales este comportamiento negativo se mantiene en una proporción tan elevada. La hipótesis de que el contexto multipartidista aumentó los costos de negociación y, con ello, debilitó los controles de calidad, no es respaldada por los datos disponibles. Esto es así porque la promesa democrática sin sustento económico se dio tanto en la época del bipartidismo "puro", entre 1990 y 1998, como en los años más recientes de alta fragmentación partidaria. Las causas parecieran estar más relacionadas con los procesos internos y, fundamentalmente, con la falta de instrumentos para evitar esta práctica. Es decir, en la actualidad, el procedimiento legislativo no obliga a las y los diputados a aprobar solo los proyectos que cumplen con ciertos criterios de calidad, como lo sería el respaldo financiero. Tampoco hay mecanismos para exigir a los parlamentarios que rindan cuentas por votar leyes sin la debida dotación de recursos, ni dentro del Congreso ni por vías de control que puedan utilizar los electores de manera sistemática. Ello se debe a que aún no existe forma de saber cómo vota cada diputado y, por consiguiente, no es posible hacer una conexión para responsabilizarlos por sus actos.

Es preciso mencionar que el 27 de julio de 2015 se aprobó el proyecto tramitado bajo el expediente 19328, propuesto por varios diputados, que incorporó el voto nominal en el Reglamento Legislativo. Por medio de un Transitorio la reforma dispone que "el Directorio de la Asamblea Legislativa contará con un plazo de tres años para implementar el o los mecanismos necesarios para el registro de votos en que se deba consignar el nombre completo del legislador o legisladora junto con su votación, en relación con todos los asuntos conocidos por el Plenario Legislativo". Habrá que esperar la implementación de dicha reforma para hacer una evaluación adecuada.

En suma, en la legislatura 2014-2015 hubo trece leyes que ampliaron derechos ciudadanos y asignaron competencias al Estado, una de las cifras más bajas de la serie histórica. De ellas, cinco no identificaron recursos, seis sí lo hicieron y dos no los necesitaron. Esto significa que solo un 38,5\% cayó en situación de promesa democrática sin sustento económico (Gráfico 4). Aunque es un buen resultado, debe considerarse que se dio en el contexto de un reducido número de leyes aprobadas, tal y como se indicó anteriormente.

El problema de la promesa democrática sin sustento económico se torna crítico en el escenario de severo déficit fiscal que enfrenta el país. Esta práctica genera una 
Gráfico 4. Leyes en situación de promesa democrática ${ }^{a /}$ sin sustento económico, por administración

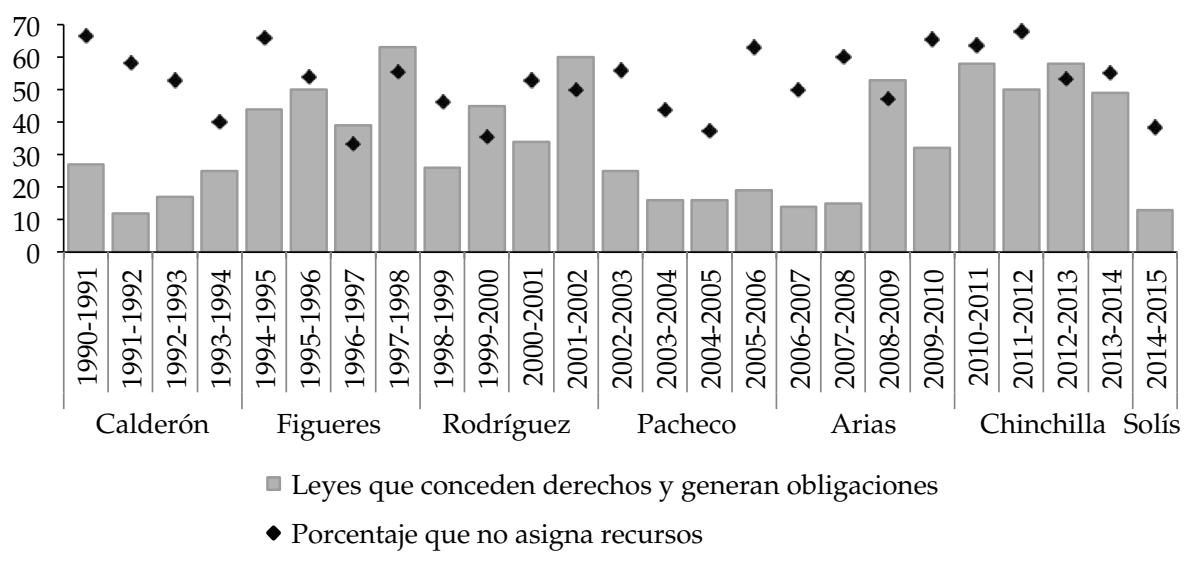

a/ Se denomina "promesa democrática" a las leyes que conceden o amplían derechos de la población o generan obligaciones para el Estado.

Fuente: Elaboración propia con base en el Vigesimoprimer Informe Estado de la Nación, 2015.

creciente presión sobre la institucionalidad del Estado que, por vía legal, está obligada a acatar cada vez más mandatos, pero sin contar con recursos frescos para satisfacer las expectativas de la población que exige su cumplimiento. En tal sentido, se trata de un círculo vicioso que tiene como origen el Congreso, y sobre el cual la ciudadanía tiene pocos mecanismos para controlar.

Debe recordarse que en Costa Rica no existe la carrera parlamentaria, y por consiguiente, el sistema político brinda muy pocos mecanismos de control directo de la ciudadanía hacia los legisladores. Por ejemplo, no existe la posibilidad de reelección legislativa, ni tampoco la revocatoria de mandato. Tampoco está en operación el sistema de voto nominal para saber de qué forma se deciden los proyectos de ley, tal y como se indicaba con anterioridad. Esta situación produce un escenario de altos niveles de libertad en el accionar de los legisladores, sin mecanismos de responsabilidad cuando el actuar no es de satisfacción de la ciudadanía. Sin duda este es uno de los principales desafíos del sistema de elección legislativa y la normativa parlamentaria.

\section{EVALUACIÓN GENERAL SOBRE EL FUNCIONAMIENTO Y CALIDAD DE LA DEMOCRACIA}

El balance político del período 2014-2015 confirma la madurez de la democracia electoral costarricense y la estabilidad institucional del Estado ante los cambios de gobierno. No obstante, el análisis realizado también confirma, tal y como lo indica la literatura especializada, que la combinación de un régimen presidencialista sin mayoría legislativa y 
un sistema multipartidista fragmentado favorece la parálisis y el enfrentamiento constante entre las fuerzas representadas. En estas circunstancias, los actores políticos han sido incapaces de procesar cambios sustantivos para atender los problemas estructurales que aquejan al país.

Ciertamente la democracia electoral funcionó y propició un nuevo episodio de alternancia en el ejercicio del poder en las presidenciales del 2014. Durante el 2015 esta evaluación se repitió con la campaña electoral para designar las autoridades municipales que se realizó en febrero de 2016. Costa Rica sigue gozando de una democracia madura que celebra elecciones con amplios grados de transparencia, y en medio de un ambiente de paz y fiesta cívica.

Con respecto a los efectos de dichas elecciones vale rescatar que, en la elección presidencial ocurrió un hecho inédito: a la Presidencia de la República llegó el Partido Acción Ciudadana, una agrupación distinta a los dos partidos que gobernaron el país durante las últimas tres décadas. Por su parte, en el poder legislativo, las elecciones produjeron la mayor fragmentación partidaria registrada desde 1953. En esta nueva conformación se desdibujaron las fuerzas hegemónicas tradicionales y se consolidó el multipartidismo. Y en el ámbito cantonal, con las elecciones de febrero de 2016, también se confirmó el formato multipartidista con el ingreso de nuevos partidos políticos compitiendo y eligiendo representantes en todo el territorio nacional. Todo ello da cuenta de un fortalecimiento de la democracia electoral, tanto a nivel nacional como local.

El análisis más estructural sobre el sistema político refleja un complejo escenario político derivado de los procesos electorales celebrados durante los últimos dos años. La información recopilada en este artículo para el período 2015 e inicios del 2016 confirma las sospechas de obstrucción y conflictividad de la nueva conformación política, que además restringe los intentos de transformación política.

Esta situación se refleja en dos aspectos básicos para la funcionalidad del sistema político. El primero refiere a las características del marco institucional y la participación de los actores dentro de él. La evidencia empírica revela que el poder ejecutivo tiene poca capacidad para gestionar los asuntos públicos, debido a la falta de cooperación en el Congreso. De hecho, Costa Rica tiene, junto con México, el nivel más bajo de América Latina en el índice de potencia institucional legislativa (IPIL), ${ }^{6}$ que mide la capacidad del ejecutivo para influir en la agenda parlamentaria (Santos, et al., 2014).

Estas condiciones adversas demandan, entonces, que la Presidencia tenga un manejo preciso y sistemático de asuntos estratégicos en espacios como las sesiones extraordinarias para convocatoria de proyectos de ley a la Asamblea Legislativa. Sin embargo, en el período analizado eso estuvo lejos de ocurrir. Un ejercicio de comparación de las primeras

6 El IPIL, elaborado por García Montero (2009), refleja no solamente las normas constitucionales sino también el procedimiento parlamentario, integrando 14 criterios institucionales que permiten evaluar en qué medida un ejecutivo tiene mayor poder de agenda. La información para los 14 ítems es agregada en cinco dimensiones, con el fin de capturar el rol del Presidente en las tres etapas del proceso legislativo (de iniciativa, constitutiva y de eficacia), así como el efecto del bicameralismo y los procedimientos legislativos extraordinarios. Estos cinco componentes son luego promediados para identificar un valor integrado (Santos, et al., 2014). 
legislaturas de los gobiernos del período 1990-2015, mostró que la administración Solís Rivera fue la que convocó más proyectos de ley durante las sesiones extraordinarias, y la que obtuvo la menor tasa de éxito en la aprobación de esas iniciativas: tan solo un 2,5\%.

A lo anterior debe sumarse que, en la conducción de otros asuntos políticos, el ejecutivo enfrentó dificultades que afectaron su imagen y desempeño. La rotación de los miembros del gabinete presidencial durante el primer año fue, igual que en la administración Chinchilla Miranda, la más alta de los últimos cinco gobiernos. Se retiraron los jerarcas de cinco ministerios clave, entre ellos Seguridad, Salud y Presidencia, así como de cinco viceministerios. Además, se destituyó a seis asesores y tres embajadores, todo en medio de conflictos de alto perfil mediático. La conjunción de estas situaciones debilitó al Gobierno y les otorgó ventajas estratégicas a grupos organizados de la sociedad y a la oposición en el Congreso, para vetar o bloquear sus iniciativas. Al final de su primer año de mandato, el Gobierno había perdido el control del Directorio Legislativo.

La segunda debilidad funcional del sistema político es el "entrabamiento", que tradicionalmente se entiende como la incapacidad para construir acuerdos legislativos pero que, en el complejo escenario actual, trasciende ese ámbito y cubre por completo al sistema político. En la Costa Rica de hoy ningún grupo puede imponer su criterio, debido a la alta interdependencia que existe entre todos los actores políticos, y la situación se ha tornado problemática porque las fuerzas involucradas no reconocen que están operando en esas condiciones $y$, por ende, atizan de manera constante la conflictividad y el desencuentro. Este fenómeno se expresa de distintas maneras. En el Congreso, por ejemplo, todas las bancadas necesitan alianzas para aprobar sus proyectos, pues ninguna por sí misma cuenta con mayoría. En el pasado el esquema bipartidista favorecía la construcción de mayorías para la toma de decisiones, pero en la nueva conformación multipartidista ello no ha sido posible, tal como muestran los indicadores de desempeño legislativo analizados.

En el fondo el problema tiene que ver con la gestión política responsable de quienes están representados. La clase política ha sido incapaz, de momento, de conformar bloques partidarios que permitan construir mayorías legislativas para la toma de decisiones, tal y como ocurre en otras democracias maduras que también conviven con multipartidismo, como por ejemplo Francia.

Lo anterior también afecta las iniciativas del ejecutivo, que depende de la cooperación del Congreso y del logro de acuerdos con grupos sociales y gremios empresariales que en los últimos años han adquirido poder de veto sobre el mandato gubernamental. Y lo mismo sucede con otros actores que protestan a diario, pues la atención de sus demandas depende de lo que consigan negociar con el Gobierno y otros sectores, como ocurre en los casos de los transportistas, los taxistas y los porteadores, por ejemplo.

En la práctica, esto significa que todos los grupos involucrados carecen de poder de decisión por sí solos, y cada vez más requieren mecanismos que permitan la cooperación y la construcción de alianzas para avanzar en sus agendas. El resultado evidente de este escenario es la "anulación" de los actores políticos y sus iniciativas, pues, al depender 
unos de otros, se encuentran sumidos en el plano de la inacción real. Este es quizás, el principal desafío político que enfrenta Costa Rica en la actualidad.

\section{BIBLIOGRAFÍA}

Alfaro-Redondo, Ronald. 2015. Perfil de participación de votantes en elecciones municipales. Contribución especial realizada para el Vigesimoprimer Informe Estado de la Nación. San José: PEN.

CIEP. 2015. Informe de Encuesta Sociopolítica de noviembre 2015. San José: CIEP-UCR.

2015. Informe de Encuesta Sociopolítica de agosto 2015. San José: CIEP-UCR.

2015. Informe de Encuesta Sociopolitica de abril 2015. San José: CIEP-UCR.

2014. Informe de Encuesta Sociopolítica de noviembre 2014. San José: CIEP-UCR.

2014. Informe de Encuesta Sociopolitica de julio 2014. San José: CIEP-UCR.

Feoli, Ludovico. 2008. Comparación de la oferta y la demanda legislativa en Costa Rica durante el 2007. Ponencia preparada para el Decimocuarto Informe Estado de la Nación. San José: PEN.

2009. Comparación de la oferta y la demanda legislativa en Costa Rica durante el período 2006-2009.

Ponencia preparada para el Decimoquinto Informe Estado de la Nación. San José: PEN.

2010. La gestión legislativa en Costa Rica 2006-2010. Ponencia preparada para el Decimosexto Informe

Estado de la Nación. San José: PEN.

2011. Desempeño legislativo en la primera legislatura de la administración Chinchilla. Ponencia preparada para el Decimoséptimo Informe Estado de la Nación. San José: PEN.

García Montero, Mercedes. 2009. Presidentes y parlamentos: ¿quién controla la actividad legislativa en América Latina? Madrid: Centro de Investigaciones Sociológicas.

Gómez-Campos, Steffan; y Murillo, Juan Guillermo. 2015. Desempeño legislativo en el período 1990-2015. Ponencia preparada para el Vigesimoprimer Informe Estado de la Nación. San José: PEN.

Indridason, Indridi; y Kam, Christopher. 2008. "Cabinet reshuffles and ministerial drift". British Journal of Political Science 38 (4): 621-656.

Martínez-Gallardo, Cecilia. 2011. Designing cabinets: presidential politics and cabinet instability in Latin America. Notre Dame, IN: Kellogg Institute for International Studies/University of Notre Dame Press.

PEN. 2015. Vigesimoprimer Informe Estado de la Nación en Desarrollo Humano Sostenible. San José: Programa Estado de la Nación.

Santos Leonardo, Manoel; Pérez-Liñán, Aníbal; y García Montero, Mercedes. 2014. “El control presidencial de la agenda legislativa en América Latina". Revista de Ciencia Política 34 (3): 511-536.

Ronald Alfaro-Redondo es politólogo, investigador y docente universitario. Es Master en Métodos Cuantitativos de Investigación por Columbia University y Master en Ciencias Políticas por la Universidad de Pittsburgh. Licenciado en Ciencias Políticas, Universidad de Costa Rica (UCR). Es profesor de la Escuela de Ciencias Políticas, Universidad de Costa Rica (UCR), e investigador del Programa Estado de la Nación auspiciado por el Consejo Nacional de Rectores (CONARE) y la Defensoría de los Habitantes de la República. Coordinador y principal investigador del capítulo Costa Rica del Latin American Public Opinion Project. Especializado en temas participación electoral, comportamiento electoral, partidos políticos y democracia local. E-mail: ralfaro@estadonacion.or.cr.

Steffan Gómez-Campos es politólogo, investigador y docente universitario. Máster en Estudios del Desarrollo por la Jüstus Liebig Universität de Giessen en Alemania, y Licenciado en Ciencias Políticas por la Universidad de Costa Rica (UCR). Investigador Principal del Capítulo Fortalecimiento de la Democracia del Programa Estado de la Nación y profesor de la Escuela y Maestría en Ciencias Políticas de la UCR. Sus áreas de trabajo son: democracia y desarrollo, partidos políticos, elecciones, y cultura política. E-mail: sgomez@estadonacion.or.cr. 
